\title{
PYTHAGORAS OF RHEGION AND THE EARLY ATHLETE STATUES.
}

\author{
SECOND ARTICLE.
}

I.

SiNCE what I last wrote on the subject of Pythagoras of Rhegion in this Journal, ${ }^{1}$ much evidence has accumulated to verify what was then brought forward in a more or less hypothetical form. I was greatly encouraged to carry on this research by the sympathetic criticism of archaeologists both published and privately communicated, but all, with one slight exception, evidently written with the view of facilitating an increase of information, of advancing the common object-the study of classical archaeology. Among the published criticisms, I have received the greatest stimulus to continue my research from the reports ${ }^{2}$ of a lecture delivered by Professor C. T. Newton at University College, London, in January of this year; and, among the unpublished, a letter from Professor Michaelis with a full and detailed criticism; while the fact that in the Berlin Museum of Casts the 'Apollo' is now entirely severed from the 'Omphalos,' and that, in the new catalogue ${ }^{3}$ of the Museum of Casts at Munich the words 'nicht zugehörigen,' are inserted into the phrase 'Apollo auf dem Omphalos' is the most important of confirmations I have received from without: for, it was the possible, and formerly firmly maintained, association of the statue with the

1 No. I. pp. 168-201.

2 The Times of January 10th, and fuller in the Builder of the same week.
${ }^{3}$ Kurzes Verzeichniss des Museums von Gypsabgïssen, Klass. Bildwerke in Müchen, No. 218, B. 
omphalos as its base that I felt to be the only positive evidence against my hypothetical assumption.

Still, it will ever remain a most difficult task to convey to others, with anything like adequate convincing power, the actual weight of an inner conviction which has grown gradually in time, passing through many stages of individual confirmation, and confirmation, moreover, which often came from quarters where the facts seemed at first to run counter to it. Such inner workings of the mind which lead to conviction cannot, from their very organic quality, be imparted fully and at once to others, even if they are not previously biassed in having formed differing opinions on the same subject. It is like attempting to transfer to a third person the faith one has in a friend, which has arisen almost unconsciously with the first touch of sympathy, has grown with long acquaintance, and has become fixed and fastened by his actions under the most varying circumstances. Such an organism of faith and well-founded inner feeling cannot be taken asunder into words and reunited together in half-anhour's conversation, so that it will present a new organism with all the life which growth in time and under favouring circumstances has given it. To continue the simile: it is in some cases only the specialist who has the means of forming so intimate an acquaintance with certain questions of his study, it is only he who lives in that atmosphere in which he can see the subtle bearing of each smallest manifestation upon the particular question and can feel and appreciate the relation it holds to the whole-as the friend can see the weight of each trivial action in the light of the whole character of his friend. But science cannot heed the inner workings of the mind of even the greatest of its especial professors, it cannot attach any weight to the feelings of the researcher-so long as they remain feelings. It is one of the great tasks of the man of science to study, to recognise, and to enumerate the causes of his belief, recognise and impart the origin of his feelings. $\mathrm{He}$ must, by his method of exposition, force the reader to make the synthesis anew, so that he re-creates in the reader the conviction which before was only in his own mind. But if the exponent is not to depend upon subjective support he can at least claim that the reader be not subjective in the way he receives the evidence. Yet here it is frequently the case that 
each exoteric reader sets himself against making any attempt at combining into life the various arguments, but selects from them all one or a group which, by experience or disposition, lies nearest to him, and bases upon this his acceptance or rejection of an hypothesis. The nature of an hypothesis, however, generally is that it does not originate from or wholly depend upon one argument only, but that the sum of all the reasons together produce that high degree of probability.

In the present case of the identification of the Choiseul-Gouffer statue with Pythagoras of Rhegion, we must also not forget that there is a negative way of testing the tenability of the hypothesis, and we must ask: if not this, what then ? The third possibility of entirely withholding our judgment will not hold good. For the statue exists and has been the subject of published discussion (and if it had not it would be high time that it should be); and the notices concerning Pythagoras exist and have been commented upon, and an omission of this important figure in the history of Greek Art would make that history incomplete; it is therefore the duty of archaeologists to fix and make perfect our notions both about the statue and about the sculptor Pythagoras. The question then must be asked: If this statue is not an athlete, what is it? If an Apollo, enumerate the reasons for this belief, and compare them with those in favour of an athlete. For the fact of his having previously been called Apollo, does not, to say the least, make it unnecessary to prove why he is so called. There can be no question of a shifting of the burden of proof in such a case. Priority or antiquity of statement is not, as it may be in the practice of law, equivalent to a certain quantity of evidence which gives it a start in proof before all other claimant propositions. It is this very unconscious inference by analogy which makes people set themselves against a correction of an earlier statement, even though it be manifestly more probable on equal grounds of inquiry. On the contrary, we may say, that the tendency in modern times, ever since the mania for seeing subjects representing scenes from the 'mysteries' which raged even thirty years ago has subsided, has been to rob many an illustration of its divine or religious character, and to bring it much nearer the hearth and human life. Greek art represented much more of the life that was about it than was formerly supposed: the sepulchral slabs have been most in- 
structive in this respect. Many a so-called Apollo and Hermes will have to quit his divine epithet and descend to the character of a simple ephebus or a particular athlete. ${ }^{1}$

The question must further be asked: If this statue represents an athlete and is not by Pythagoras, by whom is it? Exception might be taken to the putting of this question; for it may be objected, that it may belong to a sculptor or a school unknown to archaeologists. Yet this objection will not hold good, for the host of passages in the numerous authors relating to Greek art make it more than probable that no great sculptor and school have been omitted, and no very celebrated work of such a sculptor. Now, if any athlete statue exists in as many replicas as does this statue, one is justified in concluding that it must have been, not only the work of a celebrated sculptor, but also an individual statue of much repute. Then let the answer to both these questions be compared with the reasons for this attribution of the 'pugilist' to Pythagoras of Rhegion on equal grounds, and whichever is weightier let it be considered the better hypothesis, that is, the best explanation of facts about which it is our duty to know something.

But I may hope that with the confirmation now given the subject has been, if not lifted entirely out of the sphere of the probable into the sphere of the certain, yet at least placed so high in probability that it practically is on the very boundary line between these two phases of human knowledge.

II.

It appears from the report of Mr. Newton's lecture that he ranges the arguments adduced in the first paper under two heads, those that go to prove that the statue under consideration is not an Apollo, and those that tend to show that it is an

1 But we must also take a warning from the evils of a former 'fashion,' and not, in combating this very exaggeration run to the other extreme of overhumanising Greek art, of seeing scenes from human life everywhere, and of ignoring the fact that, after all, divinities were the subjects most commonly thought worthy of artistic representation by the Greek artists. 
athlete and the work of a particular sculptor, Pythagoras. Strange to say, Mr. Newton looks with greater favour than I could have possibly expected upon the arguments I have adduced to show that the statue is an athlete and may probably be the work of Pythagoras, yet does not consider that the arguments that go to show that it is not an Apollo are so conclusive. Others, however, consider the first part of the paper to prove its point beyond any doubt, while they hesitate to accept the second half. Some archaeologists think I am right in the positive part and wrong in the negative, others, that I am right in the negative and wrong in the positive; so that between the two I am either wholly right or wholly wrong. However, I prefer to accept their joint verdict in so far as it is positive.

No evidence has been adduced to show that the conclusions I arrived at in the first paper concerning the typical head-dress of the early athletes, in contradistinction to divinities, were unfounded. These conclusions were based upon a great number of instances of ancient monuments quoted in that paper, and a considerable number which I met with in the various museums of Europe, and which I judged unnecessary to add to the list of evidence. Quite recently again I have seen several bronzes in the museum at Berlin which èntirely bear out my conclusion -nay, even serve to show that for some of the lighter games, such as the throwing of the discus, even long hair floating down the back was worn. A most noteworthy instance of this is the stelé with a diskophoros, ${ }^{1}$ an archaic monument found under the ruins of the old Themistoclean wall at Athens. At all events, I may say that I have found numerous archaic figures whose attitude, attributes, or if paintings environment, evidently show them to be athletes with the hair braided after the manner of the Choiseul-Gouffier statue; while I have not met with a single work with similar hair which, from other reasons, can be shown without a doubt to be an Apollo. It is hardly necessary to say that the enumeration of a number of busts or heads, or ignorantly restored statues, which have been called Apollos, can not be used as evidence on either side of the question, especially since the Athenian statue and the Omphalos have been shown to be in no way connected. I have vainly endeavoured to find the first instance in which this type

I Overbeck, Geschichte der Griech. Plastik., 3rd ed., vol. I. p. 152. 
of head has been described in print as that of an Apollo, and which since has fixed it in archaeological literature; and I must attribute it to the habit of early archaeologists to consider every youthful and beardless figure that came to light from the classical world to be an Apollo, as most bearded figures were named Zeus or Jupiter. But as I have before said, the prolonged continuance of a proposition put forth in a period when archaeology was comparatively in its infancy cannot be a claim to more ready acceptance. To show that this type of head is that of an Apollo, it will be necessary to adduce at least as many figures undoubtedly Apollos with this arrangement of hair as I have enumerated instances of undoubted athletes. And this will be especially called for in an instance in which we have to deal with that marked illustration of bodily strength and with that peculiar athletic attitude which is found in the Choiseul-Gouffier statue.

I may here say that an anatomist of wide reputation, commenting upon the development of the pectoral muscles and the whole of the upper part of the body of the London statue, quite recently expressed his opinion that there could be no doubt of the intention of the sculptor to accentuate the strength of the man, especially in the upper part of the body.

I must confess I was astonished to find that no notice was taken by my critics of one of the most important arguments, namely, the comnexion between the attitude of the statue and the ever-recurring typical position of the ephedros in the athletic contests. The Greeks had a firmly founded system of exercise and drill in the Palaestra for each special game, and this drill included numerous typical attitudes for each individual contest and the various stages of each contest. This drill, which

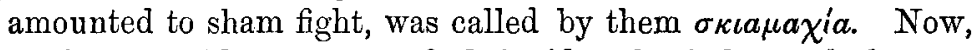
on innumerable vases we find, besides the judge and the two combatants, a third pugilist or pancratiast waiting for his turn in a constant and peculiar position, which was, we may say, 'attitude No. 1, before the fight.' The same is the case in boxing in our days, and still more in fencing. This preliminary position, moreover, with the arms and shoulders drawn back and the chest protruding, is a most rational one to the Greek's artistic eye, for it tells its story clearly; the most important part of such a man's body where his strength chiefly lies, is the 
chest, arms, and shoulders. These typical positions in the $\sigma \kappa \iota a \mu a \chi i a$ were the most ready subjects for the Greek sculptor, who chiefly made his studies in the Palaestra; and, as a matter of fact, the great number of monuments, statues, vases, figures, \&c., representing the throwing of the discus that are extant, could readily, and with great profit, be used to show all the various stages of procedure in this game, from its preparation to the expectant attitude of the thrower after the discus has left his hand. Myron chose the moment of highest tension and of complex contortion in his representation of a discobolos, and we know from the notices of ancient authors that this suited his peculiar artistic nature which delighted in the expression of extreme vitality. If he were to have represented the pugilist it is likely that like some later artists he would have chosen

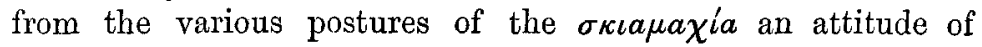
actual engagement expressive of intense exertion. Not so the earlier artists and those of a more moderate and noble taste for what is most suitable for reproduction in sculpture. They would with preference choose the monumental attitude of the preliminary posture in the pugilistic contest, that of the Ephe$d r o s$, as we see him on almost every vase representing a $\pi \nu \gamma \mu \eta^{\prime}$, and as we see him in this statue in the British Museum.

Professor Michaelis asks in his letter that I should explain to him the adjunct to the tree stump in front of the strap and the two puntelli above it, before he is prepared to accept my interpretation of the statue. Yet if I have shown that the strap on tine stem is decidedly a himas, this evidence is not nullified by my incapacity to explain the other adjuncts. One thing is certain, that the projection in front of the strap is not the extremity of the lyre of an Apollo nor of any Apollinian attribute that I can think of. Mr. Newton confirms the athletic character of the attributes in holding this projection to be a plait. This may be so, though it is not very distinct. Yet if it is a broad plait or network the question still remains, what purpose it served? And if I am bound to make some conjecture on the matter, I should with all caution draw the attention of archaeologists towards many vases with athletic scenes on which athletes carry their athletic implements (strigil, flask, \&c.) in small nets very similar to those used for lawn-tennis balls with us. In some cases these nets are represented as hanging on the 
wall together with other similar objects, and their pointed ends may bear some similarity with the end of this plaited adjunct. However, I must say, that it is not unlikely that this rough surface is meant rudely to indicate the bark of the knotty branch there chopped off, as the peculiar appearance at the bottom of the stem has no attributive meaning, but is merely an indication of a form continually to be met with in trees when the bark has split in places and a thick seam incloses the

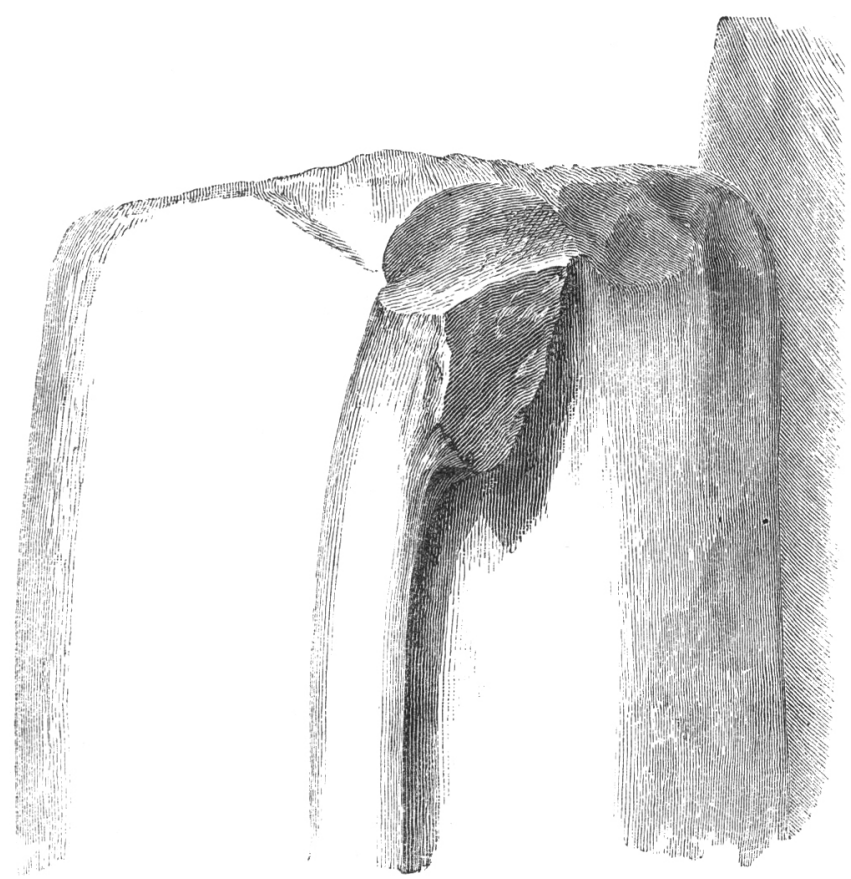

Fig. 1.

wound (if we may call it "so) in the process of growth. The same applies to the first of the puntelli alluded to by Michaelis. This is simply the stump of the lopped off branch. Similar projections can be seen on almost every tree stump of the numerous statues that have them. I am very grateful to Professor Michaelis for having led me to examine more closely the uppermost of these small projections (Fig. 1). For I believe 
that the outline of the thumb which was broken away is distinctly visible on the fracture. The measurements of the arm show that the hand would reach to the top of the tree-stump. The action of the right arm would then be most natural. Similar to the ephedros on the vase published by Gerhard, ${ }^{1}$ this

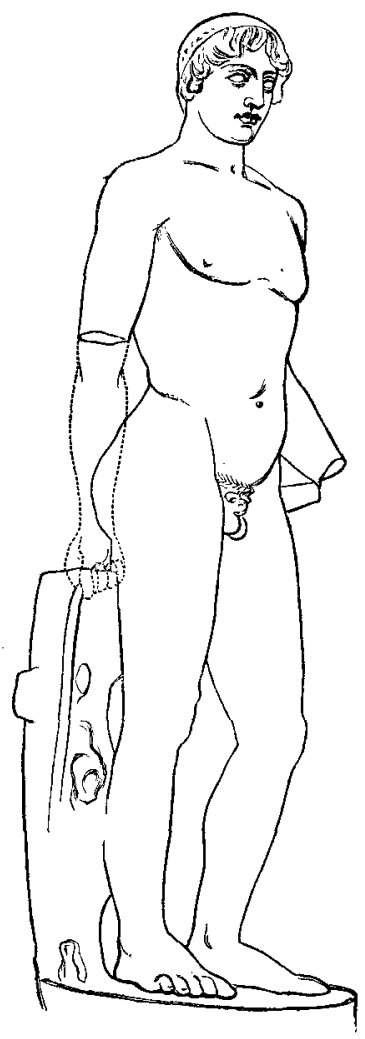

FrG. 2.

athlete would hold the himas passing through one hand between the thumb and palm "over the first joint of the forefinger, and hanging down the side of the tree. The hand would thus be touching the edge of the stump. Thus, closing his hand through

1 Antike Bildwerke, Taf. vii. 
which a strap is suspended, the thumb in a perpendicular position crossing the horizontal though upturned forefinger, will project downwards beyond the other fingers, the forefinger again projects downwards over the middle finger, the middle over the third, and so on. If the hand is turned up and examined, it presents the picture of four steps leading up to a pinnacle severed from the last by a small breadth. Now, above, and somewhat behind this fracture of the thumb, a small piece is broken away from the top of the stem proper, which would well correspond to the place where the forefinger rested on the trunk. The remainder of the hand would have been free. The nature of the fractures will well bear out this assumption, and this becomes still more probable when we bear in mind that as the himas does not hang over a branch it must have been held in some way by the athlete.

When once guided by the nature of the fractures on the tree stumps we have made this restoration, the position becomes most natural, in fact, the only possible one. The somewhat inadequate sketch (Fig. 2) will serve to illustrate this position. The arm could not have been further forward or else the shoulder would follow, while it is strongly drawn backward. The nature of the relaxed muscles of the upper arm as it is extant, show that the forearm must have gone down to the stump; or else the biceps would be contracted. If one imitates this natural position, one would immediately feel by "experiment" as it were, that this is the real position of a figure in such an attitude with regard to the upper part of the body.

That this statue is that of an athlete, and more especially a pugilist, is finally confirmed when we compare it with the marble statue of the pugilist formerly in the Palazzo Gentili, and now in the Palazzo Albani (Fig. 3). I have previously noticed this work and quoted it from Clarac, yet the outline drawing was so incomplete that its important bearing upon our question was not evident to me. The similarity of attitude in the character of chest and shoulders down to the position of the feet is quite evident upon comparison. Professor v. Duhn has very kindly sent me the proof-sheets of his new edition of Matz's Antike Bildwerke in Rom, which contains a careful notice of all accessible monuments in the private collections in Rome, and it is from him that I have learned its 


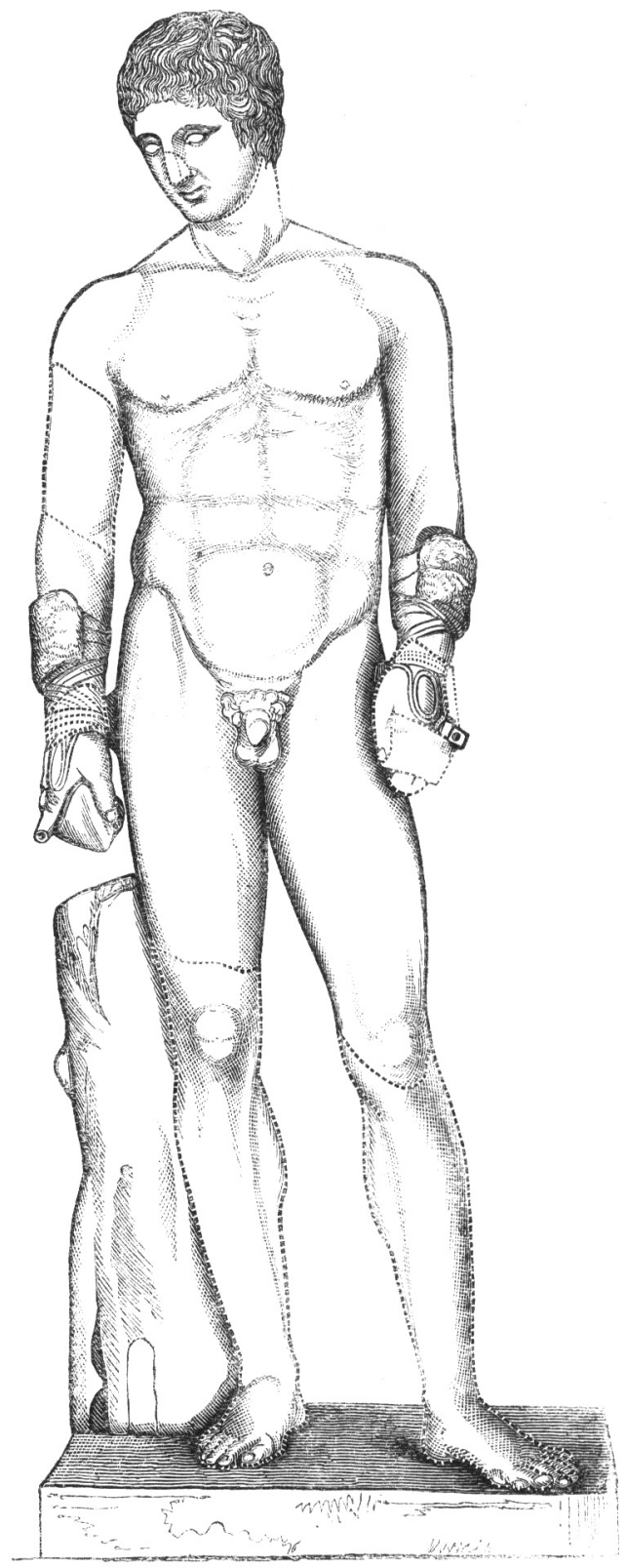

FIG. 3. 
present position: for it is published ${ }^{1}$ as being in the Palazzo Gentili. We here have the typical position of the pugilist, and, what is most important is that, though a great deal of the statue is restored, ${ }^{2}$ the right forearm, with a part of the caestus and joining puntello, is original. This statue is no doubt of later date than those we are dealing with, yet it is a modified adaptation of the same athletic type. And though there may not be any similarity in the details of style and of modelling, there is something more than similarity in the subject represented: there may be a difference in 'the how' he is represented, but there is no difference in 'the what' is represented. The relation between the style of these two pugilists, if there is any, is of no concern to us; but for the present the Gentili pugilist finally shows that the statues in the British Museum, the Patissia Museum at Athens, \&c., formerly called the ChoiseulGouffier Apollo, the Apollo on the Omphalos, \&c., are not Apollos, but pugilists.

\section{III.}

I may hope to have proved definitely that the statne in question is that of a pugilist. The second point, the attribution of this work to Pythagoras of Rhegion has received further confirmation since it was first put in a hypothetical form. It will readily be seen that the fact that this statue represents a pugilist greatly adds to the probability of its proposed attribution.

1 Cf. Matz, Antike Bildwerke in Rom, new ed. p. 319 ; Ficoroni, Breve descriz. di tre particolari statue scopertesi in Roma, l'anno 1739, viii., \&c. ; also in Raccolta d'opuscoli scientif. e flolog. pubbl. da A. Calogieri, vol, xxii, 491-506, Venezia 1740; Fea, Mise. i. exxxv. 57, and, Singolarita di Roma Moderna, 61; Gerhard, Antike Bildwerke, lxviii. 3 ; Clarac, Pl. 858 D n., $2187 \mathrm{~A}$.

2 The restoration was made for the Marchesa Gentili by Vincenzo Pacetti between 1770 and 1775 . Mem. En. ciclop. iii., 85. It is not quite certain whether the antique head belongs to this statue or not. In it are restored the nose and a piece of the left eyebrow. Further restorations are : the neck, the left hand, right upper arm, and right hand (the fore-arm, with puntello, is original), and both legs, the right from above the knee down, the left from below the knee, also trunk and base. Cf. v. Duhn, Matz, l.c. The restorations are marked with dotted lines in our engraving. 
For, among the sculptors before Pheidias, there is no other to whom such a work could be attributed, wbile Pythagoras of Rhegion was a sculptor of athlete statues par excellence, among which that of a heroified pugilist, Euthymos, was most celebrated and frequently copied. Moreover this sculptor, according to the ancients, was 'the first' to express sinews and reins and to aim at the expression of rhythm and symmetry in his works.

It is inconceivable how the 'archaising' mania should have impaired the vision of some archaeologists even with regard to this work, and it can only be explained by a circumstance to which I have previously drawn attention, namely, that the very incongruity of an athlete on an omphalos to which the statue did not properly fit, gave the whole work a want of unity which is the chief characteristic of the later archaising schools, such as that of Pasiteles. I readily take this opportunity of again impressing upon those who have had the great merit to discover a current in the later Greek art which more or less consciously strove towards the reproduction of remote and even conventional styles, that in all the work of the later copyists there is the unavoidable tendency towards introducing the innovations of their contemporary art. This tendency may be called modernising, and its involuntary influence upon the bond fide copy of a work remote in antiquity, would readily produce an effect in some respects similar to that of a new creation with a conscious attempt at reproducing the characteristics of an early art. There is nothing severely archaic in this work, no evident attempt at reproducing the imperfections of an artistic technique which is in its infancy, except perhaps the exaggeration and clumsiness of the indication of veins, and this is a most important positive argument in favour of our attribution. The general modelling in all the parts of the surface is not inferior to the composition of the whole figure. The germs of the very highest power of representing the surface of the human body in its full vitality, the naturalness of the pose, the combination of each member with the main body, while, on the other hand, a certain simplicity, almost severity, still binds this posture, and is more evidently cast over the face-all this points most definitely towards that period of transition from quaint archaism to the highest freedom of Pheidiac art. This mixture of freedom with traces 
of constraint and unobtrusive severity similarly marks the period of transition in the history of Italian painting; and the unprejudiced exclamation of the modern painter upon seeing the London statue 'Mantegna', was a great confirmation of the conclusion towards which I had been driven through so many detinite reasons. Should this statue appear too free in its style for a work of Pythagoras, I would direct the attention of the archaeologist to the Aegina marbles, and remind him of the fact that they are contemporary, and that the éprafia Airıvala was considered hard in style by the ancients ${ }^{1}$; and I would beg him to examine the extreme freedom of the works of Myran, who was but a few years younger than Pythagorns, and who was vanquished by his senior with the Delphic Pancratiast. ${ }^{2}$ And if some consider it too archaic, I would recall to their minds that, after all, Pythagoras is not yet Pheidias, nay, that he is, in the midst of this transition, one of its most powerful agents ; that he is the innovator, as is evident from the passages in which he is primus and $\pi \rho \hat{\omega} \tau o s$ to have added new freedom to his works. And they must furthermore bear in mind that the idea of constraint which was suggested to them by the back-drawn shoulders bearing some similarity to the cramped position of some very archaic works, and in which Köhler ${ }^{3}$ saw the marked archaism of the figure, has a definite intended meaning in the representation of a pugilist-ephedros, and cannot therefore be compared to the stiffness which is the result of the early artist's incapacity to represent the easy, natural 'flow of life.' The question must be asked, How did archaeologists conceive a statue by Pythagoras? And here it was most interesting to me to learn from the letter of Professor Michaelis that he had formerly thought of this very statue as an illustration of the art of Pythagoras, and had even mentioned this in some of his lectures. It is not unlikely that the appearance of Conze's essay on 'The Apollo on the Omphalos' made him desist from prosecuting his research in this direction.

The mischievous archaising theory must be dropped in

1 Paus. v. 25, 12; Quintil. Inst. Orat. xii. 10, 7, 'duriora et Tuscanicis proxima Callon atque Hegesias, iam minus rigida Calamis,' \&c. Cf. Over-

H.S.--VOL, II. beck, $S q$. pp. 81 and 82 .

2 Plin. xxxiv. 59, 8.

${ }^{3}$ As quoted in my first paper.

A A 
connexion with this statue. Its origin can be very easily accounted for: No instance of the work of the important sculptor, Pythagoras, had as yet been put forth, even hypothetically; therefore any instance of his work must be new to our eyes; and what is new and unwonted is strange; and strangeness is the chief characteristic of the work of the archaising schools. A work of Pasiteles has neither wholly the characteristics of early nor of late art, of Attic nor of Peloponnesian art. But the work of Pythagoras is neither Attic nor Peloponnesian, neither typically archaic nor post-Pheidiac, and still it has some of the characteristics of Attic art, so that Conze would attribute it to Kalamis, and many Peloponnesian elements, so that two of my correspondents lead it back to a Polykleitan archetype; and it has slight traces of archaism, so that half the authorities place it before Pheidias, and also elements of great freedom, so that the other half place it in the time of Pasiteles. But what all this uncertainty clearly means is, that we here have to deal with a school, the work of which was not known to us before, and that, in point of time, this ' neither early nor late' means the period of transition, and the "neither wholly Attic nor Peloponnesian with elements of both' means a new South Italian school which was sufficiently connected with the great Greek schools to profit by their teaching, and of sufficient independence that one of its sculptors could in important points of artistic advancement be the primus and the $\pi \rho \hat{\omega}$ тos.

Another very simple but none the less probable origin of the idea that the Apollo on the Omphalos belongs to the late archaising period, is- the peculiar proportions of the figure, very tall and with a comparatively small head. Now it is well known that the Polykleitan canon was square and massive, while Lysippus created a new canon in elongating the figure and in diminishing the size of the head. Now as there were unmistakable elements of archaism in our statue, and as the proportions seemed to correspond to the Lysippian canon, the conclusion was a very natural one, that it belonged to a time posterior to Lysippus, yet which strove back to the very earliest periods of art: i.e. that it is archaistic. Conze has quoted archaic vases in which these proportions occur; from which he rightly upholds the arehaic character of the work. Now because 
the Lysippian did thus differ from the Polykleitan canon, there is no reason to assume that there were not all kinds of human proportions in sculpture (including some like those of Lysippus) before a canon was at all established by Polykleitos. The coin from Selinus (Fig. 5) to which we shall direct our attention, and which cannot be later than the fifth century, manifests the same proportions (if not even more exaggerated in slimness) as our statue.

I should like to venture upon a wider generalisation which suggests itself to me through these considerations on the development of Greek art. It appears to me that the reactive influence of Greek culture in the colonies of Southern Italy and Sicily upon the life and culture of the mother country has not been sufficiently noticed. A colony which from its origin is in sympathy with the life and aspirations of the mother country, yet is unhampered by the fixed traditions that often act as a check to originality, is pre-formed to introduce and rapidly to live through great reformatory movements. This is true in all periods of history, and in Greece this must have been to some degree the position of Magna Graecia. Among many instances I need merely point to the activity of the philosopher Pythagoras at Croton, an idealistic yet real reform in philosophical theory no less than in social and political life. In art I had always been puzzled by the unique character of the earliest metopes from Selinus, unique alike for their boldness, as also for the evident traces of schooling, so that they are above all the contemporary works from the rest of Greece. Yet if we consider that the emigrant artist who was one of the party of settlers, though he had received strict schooling at home, worked with a certain freedom when removed from the eye of his master and the school, the mixture in these works will no longer strike us as strange. Such inferences concerning remote antiquity are not more improbable because they happen to conform with the general likelihood of human action even in our own very modern times.

Pythagoras of Rhegion was the very person wbo, from his hereditary and natural predispositions, could conciliate and bring together the striking characteristics of the great Attic and Peloponnesian schools, which, in archaic art, stood as it were opposed to one another: the strong feeling for vitality, 
which frequently, from the want of skill in the early artists, transgressed the laws of form and composition, and the Peloponnesian feeling for law and conventional regularity, which, as in the numerous reliefs from Sparta that have come down to us, does not allow the figures to attain the appearance of free vitality. Before these two elements have been well knit together in harmony we have not yet entered the period of artistic freedom. Free from the immediate pressure, from the shackles of any one school, this Rhegian of Samian origin, whose very adopted country was a mixture of both races, whose first master was a Rhegian and the second a Spartan, had all the opportunity to travel and to learn what each school could give, and not enough to be a slave to the idiosyncrasies of either of them. And so Pythagoras became, if not the founder, at least the chief representative of a school of sculpture which must have flourished for some time in the Greek colonies of the south of Italy, and whose numerous remains, found on the spot, have not yet been sufficiently studied with regard to their distinctive features.

An illustration in favour of the uniform character among the works found in the south of Italy will at the same time be the final confirmation I have to offer for the attribution of our statue to Pythagoras of Rhegion. A Didrachm of

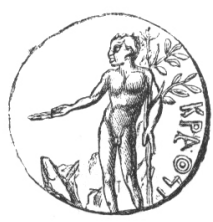

FIG. 4.

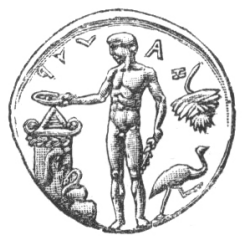

FIG. 5.

Metapontum, ${ }^{1}$ which belongs to the first half of the fifth century B.c., represents the river-god Achelous with a human body and a bearded head, which has the horns and ears of a bull (a combination of a man and a bull is a common representation of a river-god). He holds in his right hand a patera, and in his left the branch of some tree. A coin

I Millingen, Considerations sur les Monnaies de l'Ancienne Italie, \&c. Notices des Monnaies gravées, dic., suppl. P. 5, Pl. i. No. 1 ; Sambon, Recherches sur les Monnaies de la Presqu'ile Italique, dc., Naples, 1870, p. 264, Nos. 13 and 14, Pl. xix. 7 and 9 ; Jahn, Arch. Zeit. 1862 , t. 168,4, p. 321. 
from Pandosia in Bruttium ${ }^{1}$ has on the obverse a female head with inscription, TAN $\triangle O \Sigma I A$, surrounded by a laurel wreath, and on the reverse a youth (Fig. 4) holding in his right a patera or a wreath, and in his left a laurel branch; the inscription is KPA@I. The date of this coin is placed at about 430 B.C. Finally, the most important of all for comparison with our statue is the coin from Selinus, before mentioned (Fig. 5), whose similarity in attitude, proportions, indication of muscles down to the headdress, is most evident. ${ }^{2}$ It may be difficult for many ${ }^{3}$ to compare properly a figure on a small coin rubbed and effaced by age with a more than over lifesize statue with regard to the similarity of both. The points of difference between the two will be so striking that they will monopolise attention to the detriment of any claims to similarity to one who has but a small number of instances which would give him a scale of relative difference. But to a specialist, or one at all conversant with the comparative study of this class of objects, the similarity of the general type, of the definite attitude and proportions of the body, will be most manifest. I must remind the reader that, on p. 187 of the first article, I suggested as the possible restoration of this statue a palm branch in his left hand (which would account for the notch on the left leg of both the London and Athenian statues) and a wreath in his right. Both these accessories were the typical attributes of athletic victors. In this case we must substitute the himas for the wreath. Now, in the river-gods on both these coins, we seem to have the type borrowed by the inferior artist, the die-sinker, from the well-known athlete statues he saw in his own immediate environment. It has been shown in numerous instances ${ }^{4}$ that the figures on coins were generally

${ }^{1}$ Sambon, ibid., P. 342, P1. xxiii. No. 13 ; Catalogue of Gr. Coins in Brit. ifus. (edited by R. S. Poole), Italy, p. 370, No. 1.

2 P. Gardner, River Worship, \&c. Transact. of $R$. Soc. of Lit. vol. xi. p. 173.

3 Whoever has been ealled upon for the first time to look through a microscope to notice the likeness between minute structures, will see how much practice it needs to perceive similarity in such instances. I have ever found it more difficult to teach people to perceive similarity than difference. Perhaps because the perception of likeness is more a matter of feeling, while difference is more a matter of the intellect.

4 e.g., the Athenian coins with regard to the reproduction of the Promachos, the Tyrannicides by Kritios Nesiotes, the Eirene with the infant Plutos by Kephisodotos the Elder, \&c. 
taken from some well-known and celebrated work. But, one might ask, what is the connexion between these river-gods and athletes? The ever-moving, twining and twisting mountainriver of Greece presented himself to the imagination of the Greek as an active and powerful man, half a beast in his physical strength; and so, in the earlier representations, he is generally a combination of man and snake, or man and bull, from his twining movement and his roaring rush. On innumerable vases there are scenes in which heroes wrestle with rivergods, the prototype of which contest is the wrestling between Herakles and this very Acheloos. ${ }^{1}$ They are the fathers of great heroes and athletes, and the very pugilist Euthymos was made the son of the local rivèr-god Kekynos. ${ }^{2}$ But especially important is their connexion with the athletic games which they no doubt localised, and of which they shared the honour. The hair of the youths, upon their entry into manhood, is offered them. ${ }^{3}$ At Olympia the victor honours the Alpheios ${ }^{4}$ along with the twelve great gods among whom he also has his altar. ${ }^{5}$ Now, as the great Olympian games were a chronological landmark for the whole of Greece, so the local games would be for smaller districts, and this would be a definite time to strike coins. Mr. Head has made to me a very ingenious suggestion, that in connexion with these games there was also a kind of fair, where, all the neighbouring people streaming together, considerable commerce was carried on, and thus there would be a call for money and a natural time to strike it. This would be the purport of the

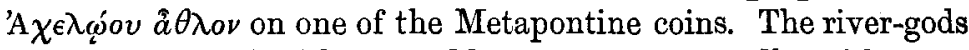
were represented either as old or young, generally with some relation to the size of the river. On the coin of Pandosia the river Krathis is a young man, so also on the Selinus coin. Now when the die-sinker desired to represent a young river-god in an athletic connexion, he would naturally, to some extent, rely upon some famous statue of an artist of repute within his country. What is more, all these 'guilds' of the higher or smaller art (though the Greeks never made this distinction, the lesser arts being to them of the highest

\footnotetext{
1 Soph. Trach. 510, \&c. Cf. Gard- 6, Paus. viii. 41, 3, \&e. ner, l.c.

Vid. first paper.

4 Pind. Ol. xi. 48.

s Il. xxiii. 142-148, Aesch. Chooph.

5 Paus. v. 14, 5.
} 
importance), such as sculptors, painters, and architects on the one hand, and gem-cutters, goldsmiths, vase-painters, and die-sinkers on the other, were all immediately connected. Nay, the same artist very frequently practised several of these together. The figures on the Pandosian and Selinuntine coin are entirely the type of an athlete, so much so that Sambon simply calls the first un ephebe. ${ }^{1}$ It will readily be seen what important confirmation for our attribution of the statue to Pythagoras of Rhegion the similarity of the coin from a neighbouring town in the same province and from a town in the vicinity in Sicily is ; for, to put it negatively to those unaccustomed to this study, no other coin from any part of Greece can offer a figure that has anything like the similarity that subsists between this coin and our statue.

Coins, then, have thus helped us to clench our previous arguments. By giving a definite locality, or group of localities, as the home of these mixed characteristics of style, which a study of the monuments themselves and their history had led us to point to as marks of a positive school, well defined though ill recognised as yet, they have enabled us to feel ourselves on safe ground. Let me only add one point more. During the last few months M. Rayet has given us an excellent reproduction of the archaic bronze head at Naples in his Monuments de l'Art Antique; Livraison II., referred to in my former paper, p. 177. A more thorough comparison of this head with the head of our statue is called for. I must remind the reader that I have throughout accepted the view that the marbles under consideration are not late and Roman, but early Greek, copies from a bronze original. Now, if our plate of the ChoiseulGouffier statue is placed beside the plate of the Naples bronze in M. Rayet's book, the extraordinary similarity, almost amounting to identity, will be most evident. I must, moreover, draw attention to the fact that this original bronze head was found at Herculaneum in Southern Italy. But these suggestions open the way to a very wide field, which it is impossible to enter upon now.

Charles Waldstein. 